\title{
The opportunities and challenges of research partnerships in teacher education.
}

\author{
Abstract \\ Collaborative research partnerships are widely recognised as being of value. This paper \\ examines the benefits, constraints and challenges of research partnerships between \\ teacher education faculties in universities and teacher employing authorities or \\ departments of education and schooling. A case study of a collaborative research \\ partnership between an education faculty and a teacher employing authority is examined \\ to illustrate the features that supported a truly collaborative partnership and also to \\ provide insights about the challenges that occurred. This research partnership was \\ studied using self-study methods. The partnership between the individual researchers \\ was examined in the context of the systemic partnership, to investigate the impact of the \\ two contexts on each other and on the partnership. Constraints and facilitators of this \\ collaborative partnership are identified in this paper. The feasibility of truly \\ collaborative partnerships between institutions with differing aims and methods of \\ operation is critiqued, using this particular partnership as an illustrative case study.
}

\section{Keywords}

Research partnerships

Teacher education

Educational partnerships

Educational systems partnerships

Teacher employing authorities 


\section{Introduction}

This paper examines a case study of a collaborative research partnership between staff of an Australian teacher education program (to be named Edfac in this paper) and a large teacher employing authority (henceforth to be identified as TEA). It interrogates some of the principles underpinning collaborative research partnerships, with a view to ascertaining how feasible they are in partnerships between institutions with differing structures, missions and agenda. The research team comprised two Edfac academics and two TEA personnel, who worked for the central office of the TEA.

A study of this partnership allows analysis of those factors that strengthen or constrain collaborative partnerships between departments of education and academia. It should be noted that this paper is written from the perspective of one of the Edfac academics for reasons that will be explained later in the paper.

\section{Research partnerships and their characteristics}

Over the last decade there has been increasing emphasis on the value of research partnerships between industry and higher education institutions. This value is believed to lie in the shared resourcing of initiatives and the bridging of gaps between theory and practice as well as ensuring research has impact for practitioners. In particular, schooluniversity partnerships are believed to improve learning for pre-service teachers, practising teachers and teacher educators (Brady, 2002; Baumfield \& Butterworth, 2007; Burton \& Greher, 2007). This paper considers the benefits and costs of research partnerships between teacher education faculties in universities and teacher employing authorities. In the paper, a case study of a research partnership is explored to illustrate the gains and the tensions that are often part of such partnerships. 
A seminal definition of partnership was suggested by Boyer (1981) as moving beyond organisational collaboration. Carlson (2001) describes the principles that Boyer elucidated for a viable partnership as being:

- $\quad$ Agreement on common problems

- $\quad$ Breaking down of the traditional academic pecking order

- $\quad$ Commitment to a sharp project focus

- $\quad$ Recognition and rewards for all participants

- Leadership that values actions over bureaucratic regulations. (Carlson, 2001, pp. 83-4)

Crossley and Holmes (2001) cite eleven principles for research partnerships which include principles on the sharing of responsibility, information and networks; the creation of transparency and trust; and the sharing of profits. A report by the NSW advisory body on quality teaching, the Ministerial Advisory Council on the Quality of Teaching (MACQT, 1998) suggests that ideal partnerships involve a recognition of interdependence and also of the features that each brings to the partnership; constructive and imaginative problem solving; a working relationship that permits risk taking; tolerance for ambiguity; and organisational structures that facilitate decision making.

There are numerous partnerships between teacher employing authorities and education faculties that observe many of the principles noted above, and yet are not truly collaborative partnerships. The term collaboration is used increasingly in education, but in diverse and ambiguous ways and in diverse settings. According to Erickson (1991, p. 229), its Oxford dictionary meaning, "to work in conjunction with another or others; to cooperate..." captures only some of the spirit of its use in education. Erickson argues it is incumbent upon participants in a collaborative venture 
to determine the meaning of the term collaborative in the context of the practice of their activities. Lasley, Matczynski and Williams (1992) suggest that collaborative partnerships are characterised by a sharing of power and agreement on desired goals. Non-collaborative partnerships are the converse, where partners pursue their individual needs at the expense of the collective need.

This paper examines a number of these principles for productive research collaborative partnerships in the context of the case study discussed here. It offers a critique of some of these principles in terms of their feasibility in a partnership between a large bureaucracy that is operating in a highly politicised climate, and a teacher education institution that has more academic freedom and different measures of productivity.

\section{The value of partnerships for teacher education research}

The present climate in education worldwide is one in which partnerships between teacher education programs and teacher employing bodies are considered to be fruitful, both as a way of reducing the gap between practice and theory and so that scarce resources can be shared in a co-operative way between two or more institutions. From the teacher education faculty perspective, such partnerships offer the opportunity to conduct research in prime sites of interest, increase the researchers' understanding of the teaching workplace, provide valuable insights to inform the teaching of education subjects, enhance the groundedness and impact of the research, and also provide much needed funding for such research. From the employing authority's perspective, participation in research partnerships provides research training and insights into the 
research design and broadens understanding of the research findings, which helps to inform policy and provide recommendations for future practice.

Different models have occurred in a number of innovative partnerships where teachers and schools conduct research, with universities acting as advisory bodies; some exemplars of Australian school-university projects where school renewal and professional learning is supported by university input are the Australian Project for Enhancing Effective Learning Project (Erikson, Brandes, Mitchell, \& Mitchell, 2005) and the Innovative Links Partnership (Peters, Dobbins, \& Johnson, 1996). In such projects, academics provide guidance to school-based projects (Sachs, 1997; Yeatman, 1996).

A significant aspect of this study is that the partnership existed between the faculty and the education employing authority at a systems level, rather than with schools, as is more commonly the case. There are some parallels between universitysystem partnerships and university-school partnerships but also some differences. The literature identifies some of the key themes regarding university-school partnerships (Brady, 2002; McLaughlin \& Black-Hawkins, 2007). These concern the different aims, contexts and understandings of the nature of research; evaluation of the research, and perhaps, most importantly, issues to do with power and voice (McLaughlin \& BlackHawkins, 2007, p.329). Cochran-Smith and Lytle (2009) highlight the value of partnerships between practitioner teachers and university academics in terms of what the universities can gain from the partnerships. They urge university staff to use such partnerships as stimuli to examine their own practice at the university, rather than focus solely on the school practice. They note the potential of practitioner research to constructively disrupt university practice. Indeed, research in schools that provides 
feedback to universities on how they are performing in the preparation of school teachers has been found to be useful to researcher-teacher educators (see for example, Cavanagh \& Prescott, 2010; Schuck 2009).

However, few studies on research partnerships concern university-system partnerships and the study discussed in this paper highlights the different themes and issues that are relevant in such partnerships. For example, as this project developed, it became clear that the partnership at the institutional level was inhibiting the partnership between the four team members.

Other professional development projects exist between education faculties and teacher employing authorities concerning the practicum, technology integration and school revisioning. However, collaborative research partnerships, such as the one described in this paper, in which both research and teaching are shared and the results of the research are needed by both institutions are not as common.

\section{The research partnership in this case study}

The larger study within which the case study was situated centred on the experiences of early career teachers. Research partnerships investigating this area are of particular value, given that seamless transition from university to school is the core business of both teacher education faculties and teacher employing authorities. Consequently, a shared goal of investigating how well early career teachers manage their first years of teaching has value for both institutions. For teacher education institutions, it provides valuable insights into the efficacy of their programs, and for education departments, recommendations on how to enhance those early years are of value in lowering attrition. 
The match of agendas in this project led to the evolution of a fruitful partnership. However, an in-depth study of the partnership offered some valuable insights regarding the complexities and challenges that often exist in research partnerships.

\section{Roles in the larger research project}

The aim of the collaborative research project was to investigate and make recommendations on how best to support early career teachers through mentoring by experienced colleagues. The study involved investigating the value of a master's level subject developing mentoring skills for the mentor teachers, and the value of the provision of a variety of networks for the mentor teachers and early career teachers so that they could interact with each other and provide mutual support. The subject was designed and taught by all four team members, although we agreed that the assessment tasks should be conducted by the two university researchers, Leah and Michelle (pseudonyms), as the university was the accrediting body for the subject. The collaborative study evolved over eighteen months.

\section{The institutions}

The activities and agendas of the four team members were guided by our two institutions. The TEA has a key responsibility for the induction and support of a large number of beginning teachers entering the state public school system each year. Research partnerships with universities are fundamental to the development of effective induction and support programs to meet the changing needs of beginning teachers in a context of advancing technology.

The university has a strength in providing higher education for professional practice. The Edfac has had many fruitful relationships with the TEA over the years, including very successful professional experience placements for pre-service teachers 
and many professional development programs. However, there has not been much true collaboration in research between the two institutions. This lack of collaboration was, and is, fairly typical in university relationships with the TEA. The model used in most partnerships tends to be one in which the university staff provide researchers and teachers as consultants who design and implement the research, while the TEA provides the initial brief, overviews the project's progress, and provides funding for the project.

It became apparent to the four team members that there was merit in studying our professional relationship in the project, for a number of reasons. The most compelling of these was the realisation that the partnership was working well as a result of a strong professional relationship built between the four researchers. Although we had all worked in research partnerships with the other institution before we embarked on this study, none of us had previously experienced the degree of agreement, and true collaboration that we were experiencing in this study. Consequently, we considered an awareness of the factors that facilitate such partnerships and factors which constrain such partnerships would be useful to others embarking on such arrangements.

\section{The partnership}

While the research partnership itself was not initially a topic for research, this became of interest. The main reason was that, for both pairs of participants, the partnership became unlike any other the four team members had experienced. A strong bond of friendship developed amongst the four of us, and complete trust and appreciation of each other's expertise was very quickly established. However, as the partnership ran its course, the TEA partners, Pat and Graham (pseudonyms) were required to put some distance between themselves and the project, and revert to more 
traditional roles of the funding partner, which had implications for the collaboration. While being very mindful that such partnerships are context-bound it is likely that an understanding of what occurred could be of use in other partnerships.

This paper will identify factors that contributed to the viability of the partnership and articulate the underlying principles that established, maintained and nurtured it. At the same time, it is useful to recognise the challenges that exist in such partnerships, and these too will be discussed.

\section{Research methodology for the study of the partnership}

A case study method was used for the study of the partnership. It was suitable for this study as it allowed "intensive, holistic description and analysis of a single instance, phenomenon, or social unit" (Merriam, 1998). Both Merriam and Stake (1995) note the importance of the boundedness of the case; in this case the study of a particular research partnership was undertaken to illustrate a more general problem in a rich, contextual and concrete way (Merriam, 1998). The case study had the characteristics suggested by Merriam (1998): it was particularistic in its focus on a particular research partnership, it was descriptive in that the end-product, this paper, describes the study in a rich and thick way, and it was heuristic in the way it described and explained how the partnership worked and how it was limited by its context.

As noted earlier, how the four team members might study our practice as partners was not one of our original research questions. As we gradually became aware that our partnership was more than just an association between a sponsoring agent and research consultants, we began to look closely at its characteristics and began our self-study of 
our practice as partners. Our research methodology for the self-study was qualitative and interpretative (Guba \& Lincoln, 1989).

The catalyst for examination of the nature of our partnership was the fact that the four of us became aware that we were experiencing a phenomenon different from any other we had experienced in previous partnerships. When we became aware that our association seemed to have many of the hallmarks of a collaborative partnership, we felt that the processes of construction of that understanding were worthy of further study. We started collecting data by holding a number of meetings at which we shared our views and reflections about the partnership. When pooling our data, we discovered that each pair had also engaged in informal discussions confirming the growing success of the partnership. We then collected additional data to add to our understanding of the nature of the partnership. These included records of our division of labour, examples of our ready exchange of information, and of our willingness to accommodate each other's view points. A major advance in our understanding of the partnership and its characteristics occurred when the university pair suggested that we capture our thinking by writing a paper about the partnership. We started revealing our thoughts and experiences to each other, for examination by the four of us, so that we could analyse the personal and institutional benefits of the partnership with each other. We also wanted to tease out the constraints and drawbacks of the partnership, a far more delicate process. We were aware that there were differences in our positions in the research, which were imposed on us by the institutional requirements of our two employers. Leah and Michelle were experienced Edfac researchers who regularly attended research conferences and presented and published papers. Pat and Graham 
were responsible for a large number of TEA projects and often held control over the finances for those projects.

\section{Findings}

\section{Positive features of the partnership}

All four of us had experience in running courses and could bring suggestions to the group about this aspect of the collaboration. However, the TEA team members looked for guidance to the Edfac team members concerning the presentation and publication of research papers, and the Edfac pair sought the TEA pair's expertise on developing a project that was relevant and useful to the TEA. Here we identify the first factor contributing to the positive personal relationships in our partnership - an accurate and acknowledged perception of each other's strengths and prior experiences.

As the project evolved so too did the responsibilities of the researchers. The project required the design, delivery, monitoring and evaluation of a master's level course to twenty sponsored experienced teachers and the design and implementation of a research project to gain understanding of the characteristics of a mentoring network. Typically the responsibility for fulfilling such project roles falls to the academic partner. Interestingly, however, this traditional division of labour did not occur. Instead the course was co-designed, delivered, monitored and evaluated by all four researchers working as a team, and the research was also conducted collaboratively. While the TEA researchers had not anticipated such a hands-on role being part of the original brief, both of them regarded the occasion as a unique professional development opportunity in the tertiary sector and were encouraged by the support and confidence their Edfac partners had in them. In turn, the Edfac researchers benefited from the TEA team's 
expertise and knowledge about relevant and current initiatives and policies. For all four researchers, our shared experience in contributing to the research and teaching was empowering - the second factor we identify as contributing to this viable partnership.

From a personal viewpoint, the TEA partners felt that the new and stimulating challenges increased their feelings of confidence and credibility. These challenges occurred mainly in the joint writing and presentation of research papers at university conferences. Traditionally, academic conference papers are written by academics. In this instance, the two TEA researchers were asked if they were interested in participating in the writing and presentation of two conference papers, and on expression of such interest, immediately became full partners in the planning and writing of the papers. For each conference, all four researchers collaborated to write the paper, and on each occasion one TEA and one Edfac researcher collaborated as a pair to jointly deliver the paper while the other pair of researchers demonstrated support by being present amongst the audience. The mutual support of partners throughout each phase of the project reinforced the value of working in a harmonious team where members have a similar work ethic and commitment. The experience suggests the third and fourth factors contributing to the viability of the partnership: the availability of mutual support in the partnership and equality of commitment to the project.

\section{Divergences, dilemmas and constraints}

The participation in presentations at the two conferences was a significant step in the partnership for the TEA researchers. In contrast to the academics, who had presented at these two conferences previously, neither of the TEA researchers had done so. The contrast between the two experiences was also illuminative in describing the 
growth of the partnership. The first conference was a conference on research methodology and, as such, was not a conference in which the TEA pair would normally have participated - the participants tended to be graduate students and academics who were interested in analysing methodological issues. Partially because the Edfac researchers saw all four partners as contributing to the research in similar ways, and partially because we thought that exploration of the partnership would be of interest at this conference, we got a commitment to the conference from the TEA pair before realising that the conference might not be the most appropriate forum for an initial paper by the four researchers. During the writing of the paper, which focused on the methodology of our study of our partnership, rather than on the partnership itself, both Pat and Graham commented on their nervousness in presenting at a methodological conference and the more comfortable feelings they were experiencing about the second conference at which the whole mentoring project was to be described. Leah and Michelle realised that we had exhibited both thoughtlessness about the specific focus of the conference and lack of sensitivity to our colleagues' areas of expertise and comfort. Although our colleagues did not express any anger or unhappiness about being involved in an area that was not core business for them, the Edfac researchers experienced feelings of responsibility for taking the partnership into an academic arena without sufficient consideration of the needs of our colleagues.

However, the two days together at the conference strengthened our partnership, increased our friendship and gave all four of us opportunities to reflect on what we each had to give to the partnership. It also brought credit to the two employing institutions, and answered the criticisms of non-academics that TEA personnel were seldom invited to be researchers in partnership with academics, and that where that did occur, it was 
done in tokenistic ways, for example, by leaving TEA employees' names off the papers, or writing them after the university researchers' names, or by having presentations given by the university personnel only. It is clear though that the university emphasis on publishing and presenting at such conferences is often at odds with the priorities of other institutions and that dilemmas re such partnerships can arise. So the first constraint in this partnership became obvious to us: the difference in our priorities, agenda and areas of activity. This difference in priorities is illustrated in the current paper: as noted earlier, this is a sole-authored paper. The reason for this is that the other Edfac researcher has since retired and the two TEA researchers did not wish to contribute to the paper as they felt it was not an appropriate area of activity for them to devoted their limited time.

The partnership discussed in this paper was exemplary in many ways: the two institutions had agreement on the problems to be investigated; Edfac and TEA personnel developed the research collaboratively, and also participated in the teaching that took place; and there was a clear and shared goal. Personal contact was always extremely warm and fulfilling. It was clear that the partnership was based on Boyer's (1981) first three principles of viable partnership: agreement on the research problematic, a democratic and egalitarian structure to the partnership and both institutions being committed to the shared research goal of enhancement of early career teachers' experiences and effective mentoring.

While the steady growth of the collaborative nature of the partnership enriched the experience for the four researchers and resulted in quality outcomes for clients, it also raised an interesting dilemma. When institutions work in partnership, where do professional loyalties and commitments foremost lie - to the partnership or to the 
employer? This possible source of tension was openly discussed amongst the four researchers who unanimously agreed that, ultimately, one's allegiances are to the employer. And so a second constraint arose: the need to ensure we were fulfilling our commitments to our employers in preference to our commitments to the project or partnership.

This constraint led to a subtle difference in the tone of the partnership and the professional relationships we had been enjoying. Whereas contributions in early discussions amongst the group were distinguished by their spontaneity and individuality, later discussions were characterised by contributions that had been caucused by each pair prior to meetings to ensure accord with employer intent. In other words, the shared recognition amongst the group that loyalties lay foremost with the employing authority, tended to limit the likelihood of spontaneous group interaction; instead it highlighted each employer's agenda. Each of us had to protect our institution's agenda and operations, and sometimes this created tension with our joint commitment to the project.

In spite of this constraint, the strength of our bond in the partnership led to each pair, on different occasions, approaching their managers to fight for the continuation of the project and to promote understanding of the other institution's position, something that led to a strengthening of institutional bonds and commitments to joint research.

As the research project gained momentum and the dilemma was tested, a further constraint was identified. In earning positive feedback from its clients and the researchers' colleagues and managers, the research project grew in its potential to meet the TEA's needs. Based upon the early findings of the research project a bigger TEA project was conceived. TEA managers felt that they needed to ensure that they were 
non-partisan in the expansion of the project. This worked against one of Boyer's (1981) principles for viable partnership: leadership that valued actions over bureaucratic regulations. The leadership of this part of the TEA did not want to be seen to be supporting a partnership with one university only, as part of its mission was to work with all universities in a non-partisan manner. This meant that opportunities had to be created for the participation of all universities in the state. In the context of such a scenario, the TEA took steps to establish credibility with all universities to maximise the likelihood of their participation in the bigger project. The TEA partners were told to minimise the time spent in collaborating in the last phase of the project with the Edfac and the collaboration underwent a change in tenor. One of the outcomes was a decision for the TEA personnel not to participate in any further publications with the Edfac. The partnership began to take on the characteristics of a consultancy with the Edfac team completing the research and submitting their results to the TEA team who then worked with their managers in using these to develop a project involving all universities.

The hands-on contribution by all partners required a large commitment of time. Regular face-to-face meetings and frequent telephone and email contact proved necessary to ensure follow-up of tasks and successful presentations. At times, the amount of time seemed onerous in the context of the partners' other work demands. However, the personal enjoyment experienced at such meetings, and the professional development of all concerned, went some way to ameliorating these constraints. In fact, one of the principles noted by Boyer (1981) suggests that recognition and rewards for all participants are central. In this partnership, the recognition by the institutions did not play a part in the sustainability of the partnership, but the rewards to the participants 
were present in the form of a stimulating and supportive collaboration and the ensuing learning from which all four participants benefited.

\section{Insights from study}

There are a number of insights that we gained from this partnership that have served us well in other partnerships. These are discussed below.

\section{Insight 1: A need for sensitivity regarding the others' roles and needs}

The partnership could not develop and grow without certain preconditions. Being sensitive to each other's roles was essential for our study, and we felt we could not embark on this study until our relationship was sufficiently robust to withstand examination. We needed to be prepared to deal with the tensions and dilemmas that might arise. Developing our understanding of these issues was important, both at a personal and institutional level.

Insight 2: A need to respect boundaries for conversations

There were several layers to the research. The study was concerned with the interactions of four people in a relationship that everyone desired to be collaborative. However, there was always a danger that total frankness could jeopardise the relationship. Consequently, it was probably true that there were aspects of the study that had to remain unexamined; to open them for scrutiny might have damaged other aspects of the study.

Insight 3: A need to protect the partnership

This point is related to the previous one. The four of us were not ready to study our relationship and partnership until we felt that we were able to withstand any critical scrutiny. However, the point discussed above remains unresolved - to protect the partnership was there a need for self-censorship? If so, how would this affect the study? 
Further we had to be prepared to accept that by studying the collaboration we might be changing it, and at worst run the risk of destroying it. The study of the partnership might lead us to territory that was best not explored. It seemed therefore, that to protect a partnership that was valuable to us, we had to skirt round critical issues. Schuck, Aubusson and Buchanan (2008) address this issue in a discussion of critical friendship amongst colleagues at a university; the maintenance of a relationship between colleagues at different institutions with different cultures is that much more delicate. This leads to the next point.

\section{Insight 4: A need to understand our commitments}

Another complication in the partnership was that we all had to be aware of our institutional responsibilities. Although we might have felt that there were actions and strategies that would have benefited the group, we also had to consider whether they would benefit the employing institutions. This too led to some restraint in our frankness about the relationship. The question of where our allegiances lay was always an unspoken subtext to the conversations. We had certain protocols to follow and could not always be frank about aspects of the collaboration which might have benefited the collaboration but not benefited one of the individual institutions. We did however, discuss this problem as an issue and carefully gave each other some tentative examples of where we saw conflicts in loyalties arising.

\section{Discussion}

This case study illuminates some of the challenges that lie in research partnerships between institutions or systems with differing goals and responsibilities. It indicates that strong professional relationships between the personnel of different 
systems are not sufficient to overcome the differing systemic perspectives. Subsequent research projects between the Edfac and TEA have indicated the enduring nature of some of the difficulties indicated in this case. These difficulties include differing perspectives on research findings that might indicate deficiencies in one institution's performance; the cost-benefits of recommendations made by researchers in the university, which need to implemented by the employing authority; and the drive for researchers to publish research findings and for employing authorities to keep findings confidential. These dilemmas highlight the complexity of such research partnerships.

Analysis of these issues and of the features of the collaboration that either supported it or constrained it are summarised here. The principles for successful partnerships are examined in the light of these features to provide a critical perspective on the feasibility of such collaborative partnerships.

There were four features of the partnership that contributed to its viability as a collaborative venture. These were:

- an accurate and acknowledged perception of each other's strengths and prior experiences;

- feelings of empowerment that are attributable to the partnership;

- support from partners when needed;

- equality in commitment to the project.

However, there were also a set of constraints that prevented the partnership from growing and developing. These included a lack of sensitivity to the needs and comfort zones of partners from different institutions with different missions; a need to prioritise the employing institutions' requirements at cost to the project or partnership; a corresponding cautiousness in collaborating freely; and the political context which 
prevented the expanded project from being developed by these two institutions and these four team members, and required a distancing of the team from each other and the project. It is arguable that the initial strength of the personal and professional relationship that developed between the members of the team together with the power of the collaboration that existed, made these constraints more obvious and disappointing

\section{Alignment with partnership principles}

It appears then, that it is not always possible to maintain effective partnerships, even when team members are committed to the principles delineated in the first part of this paper. Certainly, in this case, Boyer's first three principles which indicate the importance of shared recognition of problems; the need to break down academic barriers; and the commitment to the project were seen to be operating and effective. Boyer's fourth principle concerning recognition and reward for all participants was not clearly apparent. Although there were intrinsic rewards in being involved in the partnership, it did not seem possible to ensure extrinsic recognition and rewards for the team members, given that recognition of work diverged greatly in the two institutions: paper presentation and a strong partnership with the employing authority were highly regarded in the Edfac but not in the TEA at that time; for the TEA personnel, expanding the project to include all universities, and not having a special relationship with one faculty was essential for recognition of success. As well the political and bureaucratic nature of their employer made it necessary to interact carefully and treat the data from the project with caution. An illustration of these differing interests can be seen in the reasons that this paper is sole authored: the two TEA colleagues felt that writing the paper would be viewed as a distraction from their work in the TEA and would not be 
supported by their managers. This indicated that the fifth factor mentioned in the discussion of Boyer's principles, that of leadership that valued actions over regulations, did not appear to be present, or at any rate, was perceived as missing from the partnership.

As noted earlier, there are several key factors of a successful collaboration as indicated by MACQT (1998): these include a recognition of interdependence, an acknowledgement of the different features that each brings to the partnership, a capacity for risk taking and tolerance of ambiguity, and organisational structures that facilitate the working of the partnership. This study indicates that these factors are difficult to achieve unless the leaders and managers in the two institutions support the project and allow risk-taking. However, in the political climate in which both institutions operate, risk-taking is not encouraged. It would be valuable for institutional and political leaders to consider the benefits of effective partnerships and allow their employees the necessary level of autonomy to develop and grow the partnerships as necessary.

\section{Conclusions}

The case study had some valuable findings which provided insights concerning the challenges of research partnerships and how best to manage these. These findings and the resulting discussion suggest that although partnerships are valuable and beneficial to both education faculties and teacher employing authorities, they need to have certain characteristics to succeed:

- It is essential to acknowledge the differing cultures of the partner institutions and be sensitive to the needs and roles of the personnel from each institution. 
- The differing structures and missions of the partner institutions will often lead to different interpretations of the agreed-upon goals. Identifying the different perspectives at the beginning of the project aids in ensuring that both institutions are satisfied with the outcomes. For example, education faculties need to be aware that research recommendations come with a cost and there is often a political agenda that prevents them being enacted.

- Finally, different processes have acceptance in different areas and research into practice is valued differently in different sectors. This was seen in issues such as the differing interests in publishing papers, the amount of time that the institutions could commit staff to the project and the long-term agendas of the two institutions. Frank and open discussion at the start of the collaboration should incorporate recognition of these factors and ways of ensuring they do not impede the collaboration.

The experience with this partnership suggests that the constraints identified in this study should be examined to see how they can be minimised to allow the possibilities for a truly collaborative partnership. It highlights the importance of discussion about what each partner is seeking to gain, before the project is started. These outcomes need to be borne in mind throughout the project so that all activities are mutually beneficial. For example, if there are forums in which publications and presentations privilege academia, then other presentation forums must be found which are of value to the teaching authority. If a partnership is achieving its aims then leadership of each institution should have the courage to support this partnership. The most important challenge in establishing collaborative research partnerships between universities and education systems is the need for both institutions to benefit from the partnership. It is 
up to the participants in the partnership and their leaders and managers to ensure that this happens. Only then will such partnerships ensure worthwhile outcomes of the research for both institutions.

\section{References}

Baumfield, V. \& Butterworth, M. (2007). Creating and translating knowledge about teaching and learning in collaborative school-university research partnerships: an analysis of what is exchanged across the partnerships, by whom and how. Teachers and Teaching: Theory and Practice, 13(4), 411-427.

Boyer, E.L. (1981). School/college partnerships that work. Current Issues in Higher Education 1: 4-10.

Brady, L. (2002). School-university partnerships - What do the schools want. Australian Journal of Teacher Education, 27(1), 1-8.

Burton, S \& Greher, G. (2007). School-university partnerships: What do we know and why do they matter? Arts Education Policy Review, 109(1), 13-22.

Carlson, P. (2001). A grassroots approach to educational partnerships. THE Journal, 29(3), 83-88.

Cavanagh, M. \& Prescott, A.E. 2010, 'The growth of reflective practice among three beginning secondary mathematics teachers', Asia-Pacific Journal of Teacher Education, vol. 38, no. 2, pp. 147-159.

Cochran-Smith, M. \& Lytle, S. (2009). Inquiry as stance: Practitioner research for the next generation. New York: Teachers College Press.

Crossley, M. \& Holmes, K. (2001). Challenges for educational research: International development, partnerships and capacity building in small states. Oxford Review of Education 27(3), 395-409. 
Erikson, G., Brandes, G.M., Mitchell, I., \& Mitchell, J. (2005). Collaborative teacher learning: Findings from two professional development projects. Teaching and Teacher Education, 21, 787-798.

Erickson, G. (1991). Collaborative inquiry and the professional development of science teachers. The Journal of Educational Thought, 25(3), 228-245.

Guba, E. \& Lincoln, Y. (1989). Fourth generation evaluation. Newbury Park, CA: Sage.

Lasley, T., Matczynski, T., \& Williams, J. (1992). Collaborative and noncollaborative partnership structures in teacher education. Journal of Teacher Education, 43(4), 257-261.

MacLaughlin, C. \& Black-Hawkins, K. (2007). School-university partnerships for educational research - distinctions, dilemmas and challenges. The Curriculum Journal, 18(3), 327-341.

Merriam, S. (1998). Qualitative research and case study applications in education. San Francisco: Jossey-Bass.

Ministerial Advisory Council on the Quality of Teaching (MACQT). (1998). Raising the Standing of Teachers and Teaching. Sydney: MACQT.

Peters, J., Dobbins, B., \& Johnson, B. (1996, November). Collaborative learning through school-university partnerships. Paper presented at the Joint ERA-AARE Conference, Singapore.

Sachs, J. (1997). Renewing teacher professionalism through innovative links. Educational Action Research, 5, 449-462.

Schuck, S. (2009). How did we do? Beginning teachers teaching mathematics in elementary schools. Studying Teacher Education, 5(2), 113-123. 
Schuck, S., Aubusson, P. \& Buchanan, J. (2008). Enhancing teacher education practice through professional learning conversations. European Journal of Teacher Education, 31(2), 215 227.

Stake, R. (1995). The art of case study research. Thousand Oaks, Calif: Sage.

Yeatman, A. (1996). Building effective university-school partnerships: issues and possibilities. Forum of Education, 51 (2), 21-32. 